Rev. Bras. Saúde Prod. Anim., Salvador, v.14, n.3, p.546-557 jul./set., 2013 http://www.rbspa.ufba.br ISSN 15199940

\title{
Lisina digestível para suínos machos castrados submetidos a estresse por calor dos 95 aos $115 \mathrm{~kg}$
}

\author{
Digestible lysine levels for barrows housed in ambient of heat stress from 95 to $115 \mathrm{~kg}$ \\ of weight
}
SOBRINHO, Diomar Claudio dos Santos ${ }^{1 *}$; OLIVEIRA JÚNIOR, Gregório Murilo de ${ }^{1}$; RONER, Márcia Nunes Bandeira ${ }^{1}$; FERREIRA, Aloízio Soares ${ }^{2}$; OLIVEIRA, Aline Guimarães de ${ }^{1}$; SANTOS, Wilams Gomes dos ${ }^{2}$; GOMIDE, Ana Paula Cardoso ${ }^{2}$; MORAIS, Juciléia Aparecida da Silva ${ }^{1}$

\footnotetext{
${ }^{1}$ Universidade Federal de Sergipe, Núcleo de Pós Graduação, Departamento de Zootecnia, São Cristovão, Sergipe, Brasil.

${ }^{2}$ Universidade Federal de Viçosa, Centro de Ciências Agrárias, Departamento de Zootecnia, Viçosa, Minas Gerais, Brasil.

*Endereço para correspondência: diovet@ig.com.br
}

\section{RESUMO}

Com o objetivo de avaliar diferentes níveis de lisina digestível 35 suínos machos castrados com peso inicial de $95,6 \pm 1,1 \mathrm{~kg}$ e mantidos em salas bioclimáticas reguladas à $32^{\circ} \mathrm{C}$ foram distribuídos em um experimento com delineamento inteiramente casualizado dentro de cinco níveis de lisina digestível $(0,66 ; 0,78 ; 0,90 ; 1,02$ e $1,14 \%)$ sete repetições e um animal por unidade experimental. $\mathrm{O}$ fornecimento de ração foi realizado duas vezes ao dia e restrito pelo menor consumo dentro de cada repetição. $\mathrm{O}$ peso final, o consumo de ração médio diário, a espessura de toucinho, a profundidade de músculo, a área de olho de lombo e o percentual de carne na carcaça não foram afetados pelos níveis de lisina digestível. Houve tendência quadrática sobre $\mathrm{o}$ ganho de peso $(\mathrm{P}=0,08)$, deste modo, a conversão alimentar apresentou efeito quadrático $(\mathrm{P}=0,05)$, os quais estimaram níveis de 0,99 e $0,98 \%$ de lisina digestível, correspondentes aos consumos estimados de 23,04 e 26,21g/dia de lisina digestível, respectivamente. Os níveis de lisina digestível também afetaram de forma quadrática o peso e o rendimento de carcaça; os quais foram estimados em $0,95 \%$ e em $0,86 \%$ de lisina digestível, respectivamente. Houve redução linear no peso relativo do intestino delgado. Conclui-se que o nível de lisina digestível para suínos machos castrados em fase de terminação e mantidos sob estresse por calor é de $0,98 \%$.

Palavras-chaves: aminoácidos, carcaça de suínos, estresse térmico, exigência nutricional, qualidade de carne, terminação tardia

\section{SUMMARY}

With the objective of evaluated different digestible lysine levels 35 castrated male pigs with initial weight of $95.6 \pm 1.1 \mathrm{~kg}$ and housed in bioclimatic rooms regulated at $32^{\circ} \mathrm{C}$ were distributed in experimental design of randomized blocks into of five digestible lysine levels $(0.66 ; 0.78 ; 0.90 ; 1.02$ and $1.14 \%)$, seven replications and one pig per experimental unit. The supply of feed was realized twice per day and restricted by lesser feed intake within each repetition. The final body weight, average daily feed intake, backfat thickness, muscle depth rate, longissimus dorsi muscle area and carcass meat percentage were not affecteed by digestible lysine levels. There was quadratic trend on average weight gain $(\mathrm{P}=0.08)$ and this way, the feed conversion showed a quadratic effect $(\mathrm{P}=0.05)$, which estimated digestible lysine levels of 0.98 and $0.99 \%$, corresponding at estimated intake of 23.04 and $26.21 \mathrm{~g}$ /day of digestible lysine, respectively. The digestible lysine levels also showed quadratic effect on the weight and yield of carcass, which were estimated in 0.95 and $0.86 \%$ of digestible lysine, respectively. There was linear decrease in small intestine relative weight. The digestible lysine level for finishing phase barrows and housed under heat stress is $0.98 \%$.

Keywords: amino acids, pigs carcass, heat stress, nutritional requirement, meat quality, slow-finishing 


\section{INTRODUÇÃO}

Com o objetivo de aumentar a percentagem de carne na carcaça e reduzir a deposição de gordura, houve intenso melhoramento genético dos suínos nos últimos anos (BATISTA et al., 2011). Entretanto, este aumento no percentual de massa muscular pode fazer com que os suínos se tornem mais susceptíveis à elevação da temperatura quando alojados acima da zona de conforto. De acordo com Kiefer et al. (2010), a temperatura proposta como ideal para suínos em terminação é de 18 a $23^{\circ} \mathrm{C}$

As temperaturas no Brasil tendem a se manterem altas na maior parte do ano, e por isso, na tentativa de minimizar o estresse causado pelo calor, o organismos dos suínos utilizam de mecanismos fisiológicos tais como alterações no peso dos órgãos, na frequência respiratória (MANNO et al., 2006) temperatura retal (PATENCIE et al., 2005) e, também, de mudanças comportamentais como redução do consumo alimentar e maior ingestão de água (KERR et al., 2003), mudanças estas que podem acarretar em perdas qualitativas (RODRÍGUEZ-SÁNCHEZ et al., 2009) e quantitativas na carcaça.

Tem sido constatado que animais sob estresse calórico sofrem aumento na frequência respiratória para proporcionar perdas de calor por meio evaporativo e assim, manter o equilíbrio térmico corporal (FURLAN \& MACARI, 2002). De acordo com Rodrigues et al. (2010) a dissipação de calor pela respiração ocorre na tentativa de evitar o aumento da temperatura interna que pode se refletir em aumento da temperatura retal. Tais situações podem modificar as exigências nutricionais em função do ambiente, e estão associadas à redução no desempenho em resposta das modificações metabólicas ocasionadas pelo aumento da temperatura ambiental e pelo custo energético de mantença (REZENDE et al., 2006).

Tais situações podem alterar as necessidades de lisina digestível em suínos sob estresse por calor quando comparados a suínos alojados em condições de conforto térmico; pois aumentos na taxa de deposição proteica estão relacionados à maior demanda de lisina, indicando que a exigência desse aminoácido seja alterada em função das condições ambientais (MARINHO et al., 2007). Assim, as necessidades de lisina podem ser modificadas em função do ambiente e também por maior aporte nutricional deste aminoácido em razão de maior deposição proteica na carcaça (ANDRETTA et al., 2011; APPLE et al., 2004).

Neste contexto, objetivou-se com este experimento determinar o nível ideal de lisina digestível para suínos em terminação e mantidos ambiente de estresse por calor.

\section{MATERIAL E MÉTODOS}

$\mathrm{O}$ experimento foi realizado no setor de suinocultura da Universidade Federal de Viçosa, em Viçosa, Minas Gerais durante os meses de março e abril de 2012. O experimento foi aprovado pelo comitê de ética da universidade.

Foram utilizados 35 suínos mestiços (Landrace $\mathrm{x}$ Large White) machos castrados, em fase de terminação, com peso inicial de $94,9 \pm 1,6 \mathrm{~kg}$ e peso final de $115,3 \pm 2,71 \mathrm{~kg}$ distribuídos em delineamento inteiramente casualizado dentro de cinco níveis de lisina digestível $(0,66 ; 078 ; 0,90 ; 1,02$ e $1,14 \%$ ), sete repetições e um animal por unidade experimental, mantidos em 
salas bioclimáticas com regulação da temperatura ambiental para ser de $32^{\circ} \mathrm{C}$. Os animais foram alojados em gaiolas metálicas suspensas, com piso ripados e laterais teladas, providas de comedouro e bebedouro tipo chupeta, mantidas em sala de alvenaria, com janelas de vidro tipo basculantes, teto com forro de madeira e telhas de barro tipo francês.

A temperatura interna da sala foi mantida por meio de um conjunto de seis campânulas elétricas distribuídas em dois corredores da sala, a aproximadamente $40 \mathrm{~cm}$ do piso, ligadas a um termostato regulado para manter a temperatura em $32^{\circ} \mathrm{C}$. A renovação de ar no ambiente interno era realizada diariamente a cada 1 hora por meio de dois exaustores localizados nas paredes laterais da sala.

As condições internas da sala foram monitoradas diariamente utilizando-se termômetros de máxima e de mínima, de bulbo seco e úmido e de globo negro, mantidos em uma gaiola vazia disposta no centro da sala à meia-altura do corpo do animal. As leituras dos termômetros foram convertidas em Índice de Temperatura Globo e Umidade (ITGU) de acordo com metodologia descrita em Buffington et al. (1981) para caracterizar o ambiente térmico ao qual os animais foram submetidos. ITGU $=t g$ $+0.36 \mathrm{td}+41.5$; onde tg $=$ temperatura do termômetro de mercúrio inserido em globo negro e, td = temperatura do termômetro de bulbo seco e úmido.

A temperatura retal foi aferida por meio de termômetro clínico veterinário, introduzido no reto do animal durante um minuto, as 10 e às 15 horas a cada 5 dias. Nesses mesmos dias e horários, também foi realizado o registro da frequência respiratória por meio da contagem dos movimentos do flanco do animal durante 30 segundos, multiplicando por dois para correção destes valores para um minuto. As dietas experimentais foram formuladas seguindo-se as recomendações contidas em Rostagno et al. (2011), exceto com relação à lisina digestível e ao teor proteico cujo nível usado foi de $15,2 \% \quad$ (Tabela 1). As relações aminoacídicas atenderam ou excederam as recomendações para suínos em fase de terminação conforme exigências contidas também em Rostagno et al. (2011).

Quatro dias antes de se iniciar o experimento foi realizado um período de adaptação onde os animais consumiram ração basal e água à vontade. Durante este período o consumo de ração foi mensurado para se determinar o consumo padrão ( $\mathrm{kg} /$ dia/animal) no primeiro dia do experimento e verificar apenas o efeito da lisina digestível sobre os animais. Após a adaptação, os animais foram pesados e distribuídos de forma aleatória dentro dos tratamentos experimentais. $\mathrm{O}$ fornecimento de ração foi determinado pelo menor consumo aferido dentro de cada repetição durante o período de adaptação e aumentado a cada três dias sem que houvesse sobras até o final do experimento que teve duração de 21 dias. O consumo médio de ração foi calculado em função do consumo total no período dividido pela duração do experimento. A ração foi umedecida e fornecida em duas refeições diárias, as 07 e às 16 horas.

Os animais foram pesados no início e no final do experimento para a determinação do ganho diário de peso e da conversão alimentar.

Ao término do experimento, os animais foram submetidos a jejum de sólidos por 24 horas. Previamente ao abate, os animais foram novamente pesados para determinar o rendimento de carcaça e, em seguida, abatidos por insensibilização elétrica e sangria de acordo com as recomendações contidas em Brasil (2000). 
Rev. Bras. Saúde Prod. Anim., Salvador, v.14, n.3, p.546-557 jul./set., 2013 http://www.rbspa.ufba.br ISSN 15199940

Tabela 1. Composições centesimais e calculadas das dietas experimentais

\begin{tabular}{lccccc}
\hline \multirow{2}{*}{ Ingredientes (\%) } & \multicolumn{5}{c}{ Níveis de Lisina digestível } \\
\cline { 2 - 6 } & 0,66 & 0,78 & 0,90 & 1,02 & 1,14 \\
\hline Milho Grão (7,88\%) & 72,426 & 72,426 & 72,426 & 72,426 & 72,426 \\
Farelo de Soja (45\%) & 20,566 & 20,565 & 20,565 & 20,565 & 20,565 \\
Óleo Vegetal & 2,799 & 2,799 & 2,799 & 2,799 & 2,799 \\
Fosfato Bicálcico & 1,277 & 1,277 & 1,277 & 1,277 & 1,277 \\
Calcário & 0,899 & 0,899 & 0,899 & 0,899 & 0,899 \\
Sal & 0,356 & 0,356 & 0,356 & 0,356 & 0,356 \\
L-Lisina HCl & - & 0,154 & 0,308 & 0,462 & 0,615 \\
DL-Metionina & - & - & 0,071 & 0,144 & 0,217 \\
L-treonina & - & 0,001 & 0,083 & 0,165 & 0,247 \\
L-Triptofano & - & - & 0,001 & 0,023 & 0,045 \\
L-Valina & - & - & - & 0,050 & 0,137 \\
Min-suíno & 0,100 & 0,100 & 0,100 & 0,100 & 0,100 \\
Vit-suíno & 0,100 & 0,100 & 0,100 & 0,100 & 0,100 \\
BHT & 0,015 & 0,015 & 0,015 & 0,015 & 0,015 \\
Caulim & 1,462 & 1,307 & 0,999 & 0,618 & 0,200 \\
\hline Total & 100,00 & 100,00 & 100,00 & 100,00 & 100,00 \\
\hline Energia metabolizável (kcal/kg) & 3300 & 3300 & 3300 & 3300 & 3300 \\
Energia líquida (kcal/kg) & 2539 & 2539 & 2539 & 2539 & 2539 \\
Proteína bruta (\%) & 15,3 & 15,3 & 15,3 & 15,3 & 15,3 \\
Lisina digestível (\%) & 0,660 & 0,780 & 0,900 & 1,020 & 1,140 \\
Met. + Cist. Digestível(\%) & 0,470 & 0,470 & 0,540 & 0,612 & 0,684 \\
Treonina digestível (\%) & 0,522 & 0,523 & 0,603 & 0,683 & 0,764 \\
Triptofano digestível (\%) & 0,161 & 0,161 & 0,162 & 0,184 & 0,205 \\
Valina digestível (\%) & 0,657 & 0,657 & 0,657 & 0,704 & 0,787 \\
Fósforo disponível (\%) & 0,325 & 0,325 & 0,325 & 0,325 & 0,325 \\
Cálcio (\%) & 0,723 & 0,723 & 0,723 & 0,723 & 0,723 \\
Sódio (\%) & 0,160 & 0,160 & 0,160 & 0,160 & 0,160 \\
\hline
\end{tabular}

Fornecendo por kg de dieta: $100 \mathrm{mg}$ de ferro; $10 \mathrm{mg}$ de cobre; $1 \mathrm{mg}$ de cobalto; $40 \mathrm{mg}$ de manganês; $100 \mathrm{mg}$ de zinco e $1,5 \mathrm{mg}$ de iodo.

${ }^{2}$ Fornecendo por kg de dieta: $8,000 \mathrm{UI}$ de vit, $\mathrm{A} ; 1,200 \mathrm{UI}$ de vit, $\mathrm{D}_{3}$; 20UI de vit, E; $2 \mathrm{mg}$ de vit, $\mathrm{K}_{3} ; 1 \mathrm{mg}$ de vit, $\mathrm{B}_{1} ; 4 \mathrm{mg}$ de vit, $\mathrm{B}_{2} ; 22 \mathrm{mg}$ de ácido nicotínico; $16 \mathrm{mg}$ de ácido pantotênico; 0,50mg de vit, $\mathrm{B}_{6}$; $0,020 \mathrm{mg}$ de vit $\mathrm{B}_{12} ; 0,4 \mathrm{mg}$ de ácido fólico; $0,120 \mathrm{mg}$ de biotina; $400 \mathrm{mg}$ de colina e $30 \mathrm{mg}$ de antioxidante.

Posteriormente, procedeu-se a depilação, toalete e abertura da carcaça para a evisceração. Ao final da linha de abate as carcaças foram pesadas para a determinação do peso e do rendimento de carcaça, em seguida foram divididas longitudinalmente ao meio. Após 24 horas em câmara fria foi realizado um corte na meia carcaça esquerda a altura da $13^{\circ}$ costela para a exposição do músculo longissimus dorsi e do toucinho para cálculo da determinação da profundidade do músculo e da espessura de toucinho com o auxílio de um paquímetro de acordo com Bridi \& Silva (2007).

Para determinação da área de olho-delombo, utilizou-se uma folha transparente, a qual foi colocada por cima do músculo longissimus dorsi, contornando-o com o auxílio de uma caneta de retroprojetor de ponta fina. $\mathrm{O}$ desenho do músculo foi xerocopiado e em seguida recortados e pesados de acordo com metodologia descrita em Teixeira et al. (2011). Também foram medidos os 
comprimentos das carcaças, a partir do bordo cranial da sínfise pubiana até o bordo cranial do atlas, com o auxílio de uma fita métrica.

Os órgãos (fígado, pulmões, estômago, rins, coração, baço e intestino delgado) foram lavados e dependurados a sombra durante 15 minutos para o escorrimento da água e do sangue e o fígado foi cortado longitudinalmente para melhorar a sangria. Transcorridos 15 minutos, procedeu-se a pesagem dos órgãos e a medição do comprimento do intestino delgado conforme metodologia descrita em Kiefer et al. (2009). O peso relativo (PR) dos órgãos foi calculado da seguinte forma: PR (\%) $=$ [peso absoluto do órgão $(\mathrm{kg}) \times 100] /$ peso do animal em jejum (kg).

As variáveis avaliadas foram: temperatura retal, frequência respiratória, ganho diário de peso, consumo diário de ração, conversão alimentar, rendimento de carcaça, espessura de toucinho, percentual de carne, profundidade de músculo, área de olho-de-lombo, comprimento de carcaça, pesos de fígado, pulmões, rins, baço, coração, intestino delgado e o comprimento de intestino delgado.

Os parâmetros foram submetidos às analises de variância utilizando-se o programa Sistema de Análises Estatísticas e Genéticas - SAEG versão 9.1 (UFV, 2008). Os diferentes níveis de lisina digestível foram avaliados com base nos resultados de desempenho e característica de carcaça utilizando-se os modelos lineares ou quadráticos conforme o melhor ajuste dos parâmetros e estão descritos a seguir: modelo polinomial linear: $\hat{Y}_{i}=\beta_{0}+\beta_{1} \operatorname{Lis}_{i}+e_{i}$, em que $\hat{Y}_{i}=$ valor estimado para o $i$ ésimo nível de lisina digestível na ração, $\beta_{0}=$ constante da regressão ou intercepto, $\beta_{1}=$ parâmetro da regressão para componente linear e $e_{i}=$ erro ou desvio associado à distância entre o valor observado e o valor estimado pela equação; para a regressão polinomial quadrática: $\hat{Y}_{i}=\beta_{0}+\beta_{1} \operatorname{Lis}_{i}+\beta_{2} \operatorname{Lis}_{i}{ }^{2}+$ $\mathrm{e}_{\mathrm{i}}$, em que $\hat{\mathrm{Y}}_{\mathrm{i}}=$ valor estimado para o $\mathrm{i}$ ésimo nível de lisina digestível na ração, $\beta_{0}=$ constante da regressão ou intercepto, $\beta_{1}=$ parâmetro da regressão para componente linear, $\beta_{2}=$ parâmetro da regressão para o componente quadrático e $\mathrm{e}_{\mathrm{i}}=$ erro ou desvio associado à distância entre o valor observado e $\mathrm{o}$ valor estimado pela equação. Considerouse $5 \%$ de probabilidade e valores de $\alpha$ entre 0,05 e 0,10 , como tendência.

\section{RESULTADOS E DISCUSSÃO}

As médias das temperaturas máxima e mínima foram de $32,3 \pm 1,2^{\circ} \mathrm{C}$ e $28,9 \pm$ $1,3^{\circ} \mathrm{C}$ respectivamente, a umidade relativa média foi $78,3 \%$ e o ITGU calculado foi 81.8. Temperatura esta que caracteriza ambiente de estresse térmico para suínos em fase de terminação. De acordo com Sampaio et al. (2004) a zona de conforto térmico para suínos em terminação está entre 20 e $24^{\circ} \mathrm{C}$. A elevação da temperatura ambiental, associado à elevada umidade relativa induz ao aumento da frequência respiratória a fim de se reduzir a temperatura interna do animal e dissipar o calor produzido. Além disso, a combinação da pressão atmosférica elevada, junto à alta temperatura proporcionou um ambiente hostil aos animais; pois, de acordo com Kiefer et al. (2009), valores próximos a 81,1 caracteriza o estresse por calor para suínos em fase de terminação. Desta forma, pode-se dizer que o ambiente contribuiu de forma efetiva para alterar o desempenho e as exigências nutricionais destes animais.

Foi observado que a temperatura retal média no período da manhã foi de $39,5^{\circ} \mathrm{C}$ e no período da tarde foi de 
$39.9^{\circ} \mathrm{C}$, a média da frequência respiratória no período da manhã foi de 66,7 e à tarde foi de 76,6 mov./min., respectivamente. Deste modo, é possível que a elevação da temperatura ambiente em associação com a elevação da umidade relativa do ar também sejam os principais responsáveis pelo aumento da temperatura retal e aumento da frequência respiratória dos animais, pois foi observado que a temperatura retal permaneceu acima daquela observada em animais alojados em condições de conforto térmico. De acordo com os estudos conduzidos por Kiefer et al. (2009), suínos em terminação alojados em ambiente termoneutro apresentam temperatura retal inferior àqueles alojados em ambientes de estresse por calor (39,3 vs. $39.7^{\circ} \mathrm{C}$ ), valores similares aos deste experimento.

Em função do estresse térmico, foi observado aumento na frequência respiratória dos animais. Estes resultados foram superiores àqueles obtidos por Yan et al. (2000), os quais observaram frequência respiratória para suínos em ambientes termoneutro de 15 a 25 movimentos por minuto. Assim, pode-se inferir que suínos mantidos em estresse por calor apresentam ajustes fisiológicos para possibilitar o aumento da dissipação de calor por evaporação através do trato respiratório e reduzir a temperatura do núcleo corporal para assim, manter a homeostase térmica.

$O$ peso final dos animais não foi afetado $(\mathrm{P}>0,10)$ pelo aumento do nível de lisina digestível (Tabela 2). Entretanto, o ganho de peso médio diário apresentou tendência quadrática $(\mathrm{P}=0,08)$ até o nível 0,99\% de lisina digestível (Figura 1), possibilitando um consumo estimado em 25,34g/dia de lisina digestível.

Pode-se observar que o aumento dos níveis de lisina digestível na ração apresentou tendência em melhorar $\mathrm{o}$ ganho de peso dos animais em 14,8\% (764,7 vs. $898,0 \mathrm{~g} / \mathrm{dia})$. Este melhor ganho de peso foi possível devido a estes animais apresentarem redução percentual do intestino delgado, o que possibilitou aumentar o peso da carcaça e o rendimento de carcaça mesmo que o peso final dos animais não tenha sido afetado. Dados similares foram obtidos por Batista et al. (2011), estudando o aumento dos níveis de lisina digestível para suínos em crescimento mantidos em ambientes de estresse por calor, os quais determinaram $1,05 \%$ de lisina digestível. De acordo com Souza et al. (2011), o maior ganho de peso possivelmente se dá pela máxima expressão gênica para esta característica, (SOUZA et al., 2011). Como já era de se esperar o consumo de ração não afetou os níveis de lisina digestíveis, visto que este consumo foi controlado dentro das repetições. Entretanto, houve melhoria $(\mathrm{P}=0,05)$ na conversão alimentar até o nível de 0,98\% de lisina digestível (Figura 2), uma vez que o ganho de peso foi melhorado, possibilitando aumento na eficiência de utilização dos nutrientes e redução na conversão alimentar em $15,1 \%$ (3,37 vs. 2,86$)$, melhoria esta que corresponde a uma ingestão de 25,08 $\mathrm{g} /$ dia de lisina digestível. Contudo, Almeida et al. (2010), avaliando níveis de lisina para suínos em fase de terminação sem restrição alimentar, não observaram diferenças sobre a conversão alimentar estimando níveis de $0,88 \%$ de lisina digestível, esta divergência encontrada possivelmente pode ser explicada em função da melhoria do potencial genético dos animais em questão. 
Rev. Bras. Saúde Prod. Anim., Salvador, v.14, n.3, p.546-557 jul./set., 2013 http://www.rbspa.ufba.br ISSN 15199940

Tabela 2. Desempenho de suínos machos castrados em fase de terminação alojados em ambiente de estresse por calor em função dos níveis de lisina digestível

\begin{tabular}{lcccccccc}
\hline \multirow{2}{*}{ Variáveis } & \multicolumn{4}{c}{ Níveis de Lisina (\%) } & \multicolumn{3}{c}{ Valor de $P$} & CV \\
\cline { 2 - 7 } & 0,66 & 0,78 & 0,90 & 1,02 & 1,14 & $\mathrm{~L}^{1}$ & $\mathrm{Q}^{2}$ & $(\%)$ \\
\hline Peso inicial $(\mathrm{kg})$ & 96,44 & 94,40 & 94,50 & 94,38 & 94,90 & $\mathrm{~ns}$ & $\mathrm{~ns}$ & 3,4 \\
Peso final (kg) & 112,5 & 111,0 & 113,3 & 113,2 & 112,7 & $\mathrm{~ns}$ & $\mathrm{~ns}$ & 2,3 \\
Ganho de peso (g/dia) & 764,7 & 789,5 & 893,8 & 898,0 & 845,2 & $\mathrm{~ns}$ & 0,08 & 12,8 \\
Consumo de ração (kg/dia) & 2,58 & 2,53 & 2,56 & 2,57 & 2,57 & $\mathrm{~ns}$ & $\mathrm{~ns}$ & 1,9 \\
Conversão alimentar (g/g) & 3,37 & 3,20 & 2,86 & 2,85 & 3,03 & $\mathrm{~ns}$ & 0,05 & 13,8 \\
\hline
\end{tabular}

${ }^{1} \mathrm{~L}$ - linear; ${ }^{2} \mathrm{Q}$ - quadrático.

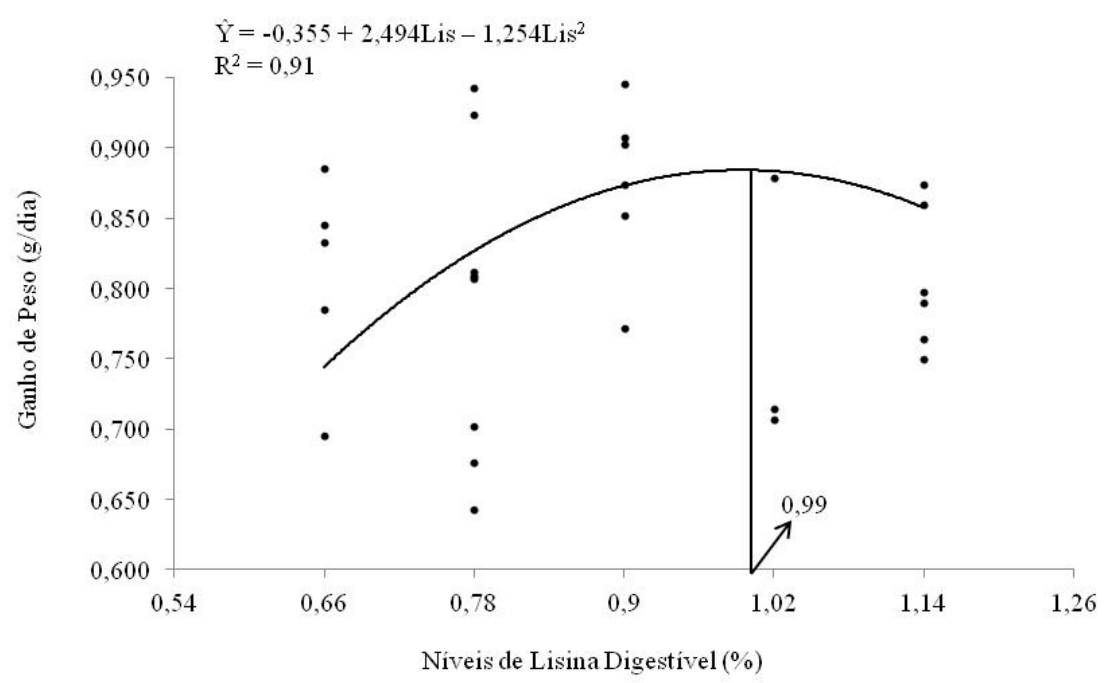

Figura 1. Ganho de peso médio diário de suínos machos castrados em fase de terminação em função dos níveis de lisina digestível

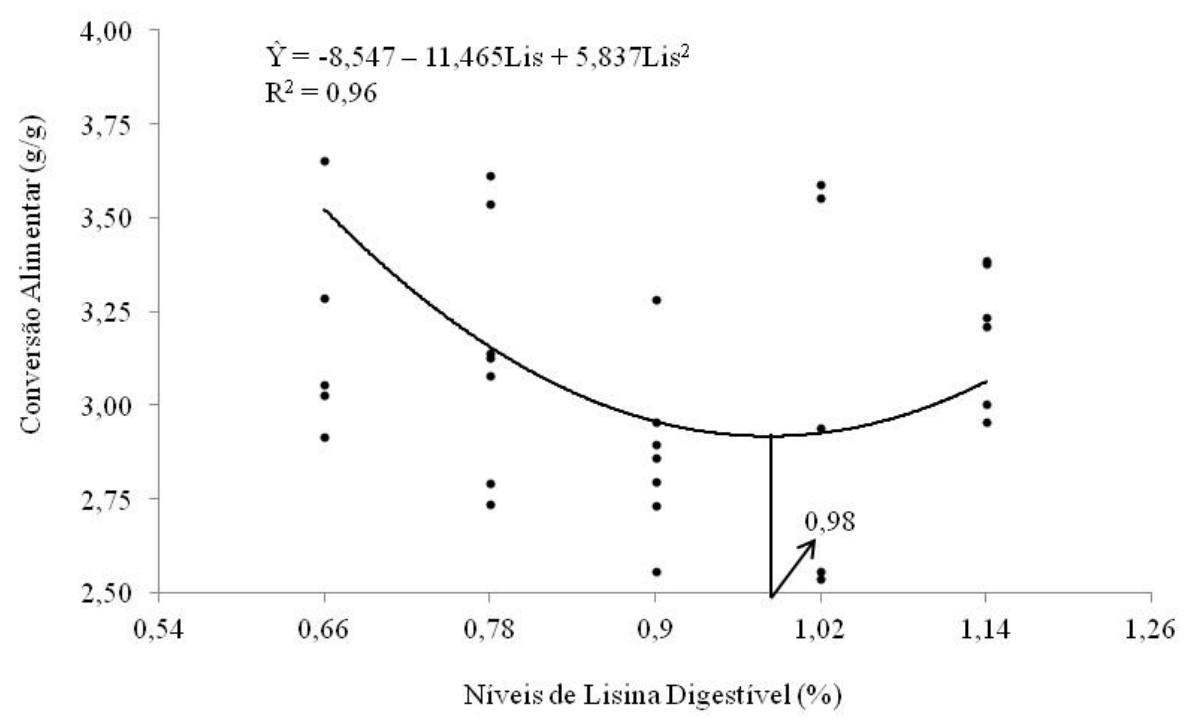

Figura 2. Conversão alimentar de suínos machos castrados em fase de terminação em função dos níveis de lisina digestível 
O peso da carcaça foi afetado de forma quadrática $(\mathrm{P}=0,02)$ com o aumento dos níveis de lisina, os quais foram estimados em 0,95\% (Tabela 3; Figura 3). O maior rendimento de carcaça pode ser explicado pelo maior peso da carcaça e também pela redução do peso do intestino delgado. Estes resultados corroboram com aqueles obtidos por, Cantarelli et al. (2009); Almeida et al. (2010); Moura et al. (2011); Souza et al. (2011). Resultados contrastantes foram observados por outros autores (KILL et al., 2003; OLIVEIRA et al., 2003; AROUCA et al., 2005), os quais determinaram $0,90 \%$ de lisina digestível, estas diferenças possivelmente seja devido a melhoria genética das linhagens dos suínos atuais, os quais apresentam maiores taxas de crescimento evidenciando seu maior potencial genético para deposição de carne.
$\mathrm{O}$ rendimento de carcaça foi afetado de forma quadrática $(\mathrm{P}=0,03)$ pelos lisina digestível, os quais foram estimados em $0,86 \%$ de lisina digestível (Figura 4). Como houve redução no peso do intestino delgado e aumento no peso da carcaça e no ganho de peso dos animais, consequentemente $\mathrm{o}$ rendimento foi afetado, aumentando-o.

Não houve efeito $(\mathrm{P}>0,10)$ dos níveis de lisina digestível sobre a espessura de toucinho no ponto $\mathrm{P}_{2}$, profundidade de músculo, área de olho de lombo (AOL) e comprimento de carcaça, e nem sobre o peso relativo do fígado, rins, coração, pulmão, baço e estômago. Contudo, o peso relativo do intestino delgado, reduziu de forma linear $(\mathrm{P}=0,01)$ à medida que se aumentou o nível de lisina digestível na dieta.

Tabela 3. Características de carcaça e pesos relativos dos órgãos em função dos níveis de lisina digestível

\begin{tabular}{|c|c|c|c|c|c|c|c|c|}
\hline \multirow{2}{*}{ Variáveis } & \multicolumn{5}{|c|}{ Níveis de Lisina (\%) } & \multicolumn{2}{|c|}{ Valor de $P$} & \multirow{2}{*}{$\begin{array}{l}\text { CV } \\
(\%)\end{array}$} \\
\hline & 0,66 & 0,78 & 0,90 & 1,02 & 1,14 & $\mathrm{~L}^{1}$ & $\mathrm{Q}^{2}$ & \\
\hline Peso da carcaça $(\mathrm{kg})$ & 90,5 & 90,8 & 92,8 & 93,3 & 91,2 & $\mathrm{~ns}$ & 0,02 & 1,8 \\
\hline Rendimento carcaça (\%) & 80,5 & 80,6 & 80,7 & 81,6 & 78,7 & ns & 0,03 & 1,7 \\
\hline Espessura de toucinho (mm) & 13,1 & 10,2 & 11,6 & 15,0 & 11,8 & $\mathrm{~ns}$ & ns & 27,5 \\
\hline Profundidade de músculo & 53,8 & 52,3 & 53,0 & 53,7 & 54,0 & $\mathrm{~ns}$ & $\mathrm{~ns}$ & 13,1 \\
\hline Carne na Carcaça & 58,3 & 60,4 & 59,6 & 56,5 & 59,2 & $\mathrm{~ns}$ & ns & 6,4 \\
\hline $\mathrm{AOL}\left(\mathrm{cm}^{2}\right)^{3}$ & 44,6 & 40,3 & 46,6 & 48,8 & 40,7 & $\mathrm{~ns}$ & $\mathrm{~ns}$ & 17,9 \\
\hline Comprimento carcaça $(\mathrm{cm})$ & 96,0 & 94,8 & 96,7 & 95,0 & 97,1 & ns & $\mathrm{ns}$ & 5,6 \\
\hline \multicolumn{9}{|l|}{ Pesos relativos $(\%)$} \\
\hline Fígado & 1,65 & 1,62 & 1,47 & 1,56 & 1,58 & ns & ns & 12,6 \\
\hline Rins & 0,29 & 0,28 & 0,27 & 0,23 & 0,30 & ns & $\mathrm{ns}$ & 12,6 \\
\hline Coração & 0,30 & 0,34 & 0,31 & 0,30 & 0,31 & $\mathrm{~ns}$ & ns & 11,5 \\
\hline Pulmão & 0,54 & 0,64 & 0,54 & 0,51 & 0,54 & $\mathrm{~ns}$ & $\mathrm{~ns}$ & 24,7 \\
\hline Baço & 0,15 & 0,19 & 0,14 & 0,12 & 0,30 & ns & ns & 61,1 \\
\hline Estômago & 0,49 & 0,48 & 0,50 & 0,49 & 0,44 & $\mathrm{~ns}$ & $\mathrm{~ns}$ & 14,0 \\
\hline Intestino Delgado & 1,45 & 1,44 & 1,28 & 1,12 & 1,01 & 0,01 & $\mathrm{~ns}$ & 13,0 \\
\hline
\end{tabular}

${ }^{1} \mathrm{~L}=$ linear; ${ }^{2} \mathrm{Q}=$ quadrático; ${ }^{3} \mathrm{AOL}=$ área de olho de lombo. 


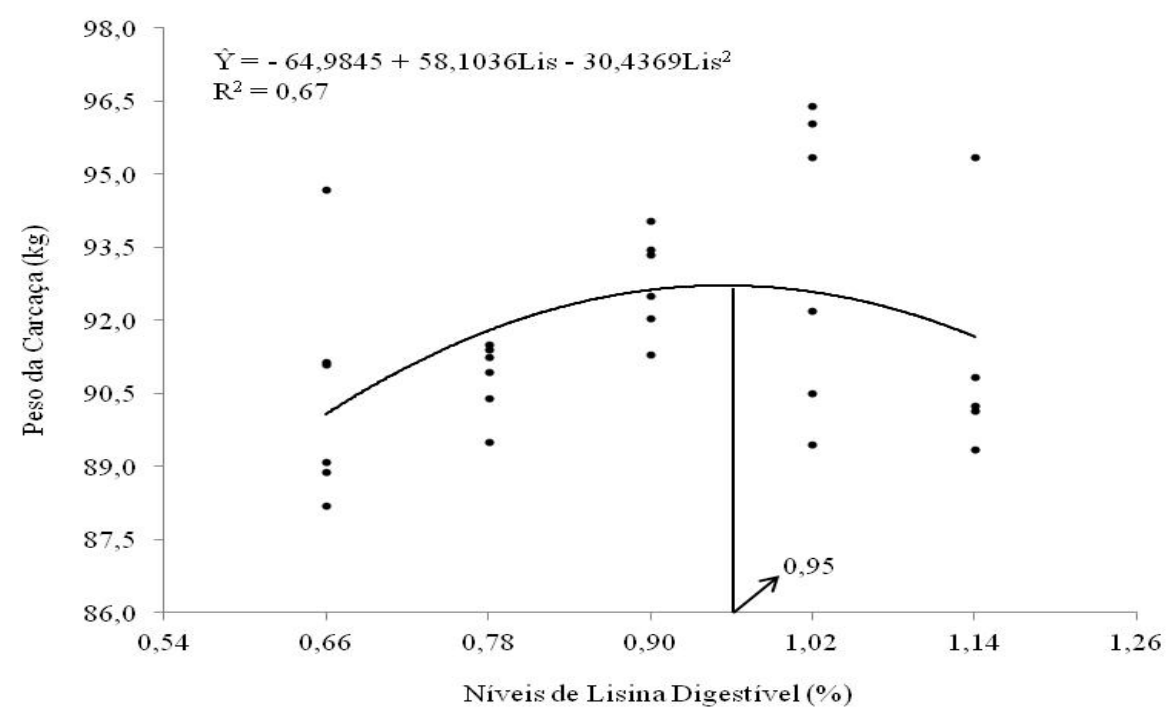

Figura 3. Peso de carcaça de suínos machos castrados em fase de terminação em função dos níveis de lisina digestível

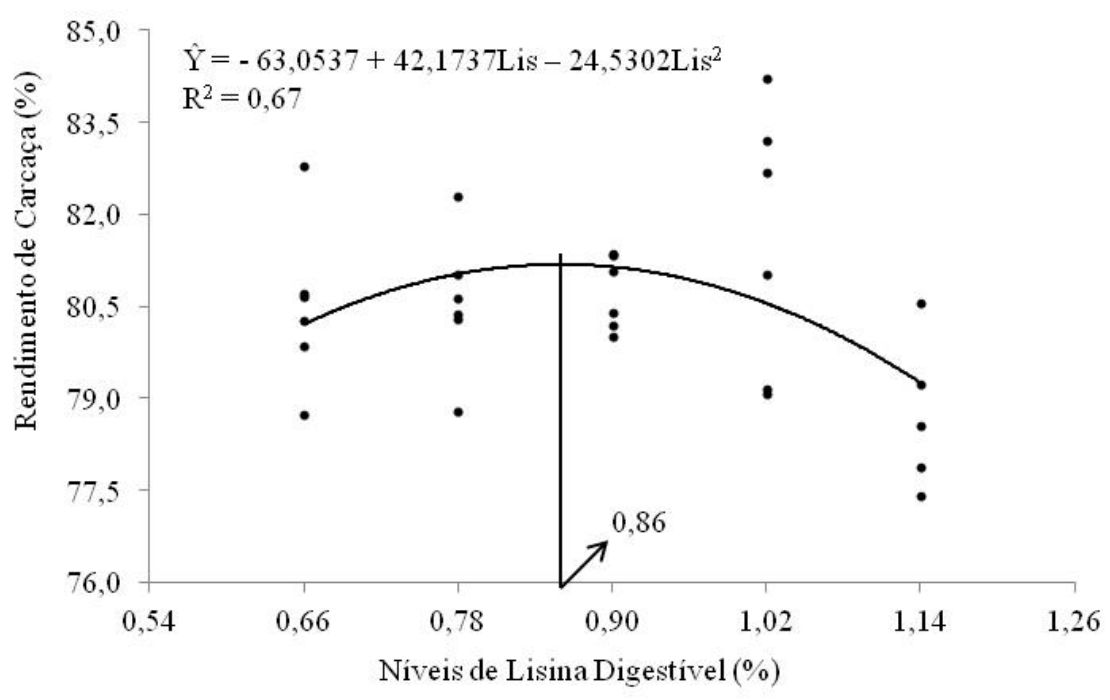

Figura 4. Rendimento de carcaça de suínos machos castrados em fase de terminação em função dos níveis de lisina digestível

É possível que o consumo de ração controlado entre as repetições seja o responsável pela espessura de toucinho se manter constante entre os níveis de lisina digestíveis estudados. Além disso, o fato destes animais estarem alojados em condições de estresse térmico, o qual promove maior consumo energético para manutenção das funções vitais, tal como a temperatura corporal, também tenha contribuído para manutenção da espessura de toucinho. Moura et al. (2011), estudando suínos sobre estresse térmico observaram resultados similares. Contudo, Santos et al. (2011), avaliando níveis de lisina digestível para suínos machos castrados dos 95 a $125 \mathrm{~kg}$, não observaram os mesmos efeitos, possivelmente por diferenças entre os animais. 
Conclui-se que o nível de lisina digestível para suínos machos castrados em fase de terminação e mantidos sob estresse por calor é de $0,98 \%$.

\section{AGRADECIMENTOS}

Os autores agradecem gentilmente ao $\mathrm{CNPq}$ (Conselho Nacional de Desenvolvimento Cientifico e Tecnológico) e ao INCT-CA (Instituto Nacional de Ciência e Tecnologia Ciências Animal) pelo aporte financeiro $e$ concessão de bolsas.

\section{REFERÊNCIAS}

ALMEIDA, E.C.; FIALHO, E.T.; RODRIGUES, P.B.; ZANGERONIMO, M.G.; LIMA, J.A.F.; FONTES, D.O. Ractopamine and lysine levels on performance and carcass characteristics of finishing pigs. Revista Brasileira de Zootecnia, v.39, n.9, p.1961-1968, 2010.

ANDRETTA, I.; LOVATTO, P.A.; SILVA, M.K.; LEHNEN, C.R.; LANFERDINI, E.; KLEIN, C.C. Relação da ractopamina com componentes nutricionais e desempenho em suínos: um estudo meta-analítico.

Ciência Rural, v.41, n.1, p.186-191, 2011.

APPLE, J.K.; MAXWELL, C.V.; BROWN, D.C. Effects of dietary lysine and energy density on performance and carcass characteristics of finishing pigs fed ractopamine. Journal of Animal Science, v.82, p.3277-287, 2004.

AROUCA, C.L.C.; FONTES, D.O.; VELOSO, J.A.F.; MOREIRA, H.F.V.; MARINHO, P.C. Exigências de lisina, com base no conceito de proteína ideal, para suínos machos castrados, dos 96 aos $120 \mathrm{~kg}$, selecionados para eficiência de crescimento. Arquivo Brasileiro de Medicina Veterinária e Zootecnia, v.57, p.104-111, 2005

BATISTA, R.M.; OLIVEIRA, R.F.M.; DONZELE, J.L.; OLIVEIRA, W.P.; LIMA, A.L.; ABREU, M.L.T. Lisina digestível para suínos machos castrados de alta deposição de carne submetidos a estresse por calor dos 30 aos $60 \mathrm{~kg}$.

Revista Brasileira de Zootecnia, v.40, n.9, p.1925-1932, 2011.

BRASIL. Ministério da Agricultura e do Abastecimento. Instrução normativa $\mathrm{n}^{\mathrm{o}}$ 3, de 17 de janeiro de 2000 .

Regulamento Técnico de Métodos de Insensibilização para o Abate Humanitário de Animais de Açougue.

Diário Oficial da República Federativa do Brasil, Brasília, DF, 24 de janeiro de 2000. Seção 1, p. 14.

BRIDI, A.M; SILVA, C.A. Métodos de avaliação de carcaça e da carne suína. Londrina: Midiograf, 97p. 2007.

BUFFINGTON, D.E.; COLAZOAROCHO, A.; CANTON, G.H.; PITT, D.; THATCHER, W.W.; COLLIER, R.J. Black globe humidity index (BGHI) as comfort equation for dairy cows. Transactions of the American Society Agricultural Engineering, v.24, p.711-714, 1981.

CANTARELLI, V.S; FIALHO, E.T; ALMEIDA, E.C; ZANGERONIMO, M.G; AMARAL, N.O.; LIMA, J.A.F. Características da carcaça e viabilidade econômica do uso de cloridrato de ractopamina para suínos em terminação com alimentação à vontade ou restrita. Ciência Rural, v.39, n.3, p.844-851, 2009. 
FURLAN, L.F.; MACARI, M.; GONZALES, E. Fisiologia Aviária aplicada a frangos de corte. 2 ed. Jaboticabal: Funesp, p.209-230. 2002.

KERR, B.J.; SOUTHERN, L.L.; BIDNER, T.D.; FRIESEN, K.G.; EASTER, R.A. Influence of dietary protein level, amino acid supplementation on environmental temperature on performance, body composition, organ weights and total heat production of growing pigs.

Journal of Animal Science, v.81, p.1998-2007, 2003.

KIEFER, C.; MEIGNEN, B.C.G.; SANCHES, J.F.; CARRIJO, A.S. Resposta de suínos em crescimento mantidos em diferentes temperaturas.

Archivos de Zootecnia, v.58, p.55-64, 2009.

KIEFER, C.; MOURA, M.S.; SILVA, E.A.; SANTOS, A.P.; SILVA, C.M.; LUZ, M.F.; NANTES, C.L. Respostas de suínos em terminação mantidos em diferentes ambientes térmicos. Revista Brasileira de Saúde e Produção Animal [online], v.11, n.2, p.496-504, 2010.

KILL, J.L.; DONZELE, J.L.; OLIVEIRA, R.F.M.; FERREIRA, A.S.; LOPES, D.C.; SILVA, F.C.O.; SILVA, M.V.G.B. Planos de Nutrição para Leitoas com Alto Potencial Genético para Deposição de Carne Magra dos 65 aos $105 \mathrm{~kg}$. Revista Brasileira de Zootecnia, v.32, p.1330-1338, 2003.

MANNO, M.C.; OLIVEIRA, R.F.M.; DONZELE, J.L.; OLIVEIRA, W.P.; VIEIRA VAZ, R.G.M.; SILVA, B.A.N.; SARAIVA, E.P.; LIMA, K.R.S. Efeitos da temperatura ambiente sobre o desempenho de suínos dos 30 aos $60 \mathrm{~kg}$. Revista Brasileira de Zootecnia, v.35,n.2, p.471-477, 2006.
MARINHO, P.C.; FONTES, D.O.;

SILVA, F.C.O.; SILVA, M.A.; PEREIRA, F.A.; AROUCA, C.L.C. Efeito dos níveis de lisina digestível e da ractopamina sobre o desempenho e as características de carcaça de suínos machos castrados em terminação. Revista Brasileira de Zootecnia, v.36, n.6, p.1791-1798, 2007.

MOURA, M.S.; KIEFER, C.; SILVA, C.M.; SANTOS, A.P.; FANTINI, C.C.; LUCAS, L.S. Energia líquida e ractopamina para leitoas em terminação sob altas temperaturas ambientais.

Ciência Rural, v.41, n.5, p.888-894, 2011.

OLIVEIRA, A.L.S.; DONZELE, J.L.; OLIVEIRA, R.F.M.; FERREIRA, A.S. MOITA, A.M.S.; GENEROSO, R.A.R. Lisina em rações para suínos machos castrados selecionados para deposição de carne magra na carcaça dos 110 aos 125 kg. Revista Brasileira de Zootecnia, v.32, n.1, p.150-155, 2003.

PATIENCE, J.F.; UMBOH, J.F.; CHAPLIN, R.K.; NIACHOTI, C.M. Nutritional and physiological responses of growing pigs exposed to a diurnal pattern of heat stress. Livestock Production Science, v.96, p.205-214, 2005.

REZENDE, W.O.; DONZELE, J.L.; OLIVEIRA, R.F.M.; ABREU, M.L.T.; FERREIRA, A.S.; SILVA, F.C.O.; APOLÔNIO L.R. Níveis de energia metabolizável mantendo a relação lisina digestível:caloria em rações para suínos machos castrados em terminação. Revista Brasileira de Zootecnia, v.35, p.11011106, 2006.

RODRIGUES, N.E.B; ZANGERONIMO, M.G.; FIALHO, E.T. Adaptações fisiológicas de suínos sob estresse térmico. Nutritime, v.07, n.02, p.1197-1211, 2010. 
RODRÍGUEZ-SÁNCHEZ, J.A.; SANZ, M.A.; BLANCO, M.; SERRANO, M.P.; JOY, M.; LATORRE, M.A. The effect of seasonality of the growingfinishing period on carcass, meat and fat characteristics of heavy barrows and gilts. Meat Science, v 83, p.571-576, 2009.

ROSTAGNO, H.S.; ALBINO, L.F.T.; DONZELE, J.L.; GOMES, P.C.; OLIVEIRA, R.F.; LOPES, D.C.; FERREIRA, A.S.; BARRETO, S.L.T.

Tabelas Brasileiras para Aves e Suínos: composição de Alimentos e Exigências Nutricionais. 3.ed. Viçosa: UFV, 2011. 252p.

SAMPAIO, C.A.P.; CRISTANI, J.; DUBIELA, J.; BOFF, C.E.;

OLIVEIRA, M.A. Avaliação do ambiente térmico em instalação para crescimento e terminação de suínos utilizando os índices de conforto térmico nas condições tropicais. Ciência Rural, v.34, n.3, p.785-790, 2004.

SANTOS, F.A.; DONZELE, J.L.; SILVA, F.C.O.; OLIVEIRA, R.F.M.; ABREU, M.L.T.; SARAIVA, A.; HAESE, D.; LIMA, A.L. Níveis de lisina digestível para suínos machos castrados de alto potencial genético dos 95 aos $125 \mathrm{~kg}$. Revista Brasileira de Zootecnia, v.40, n.5, p.1038-1044, 2011.
SOUZA, E.O.; HAESE, D.; KILL, J.L.; HADDADE, I.R.; LACERDA, E.G.; SARAIVA, A.; SILVA, F.C.O.; SOBREIRO, R.P. Digestible lysine levels in diets supplemented with ractopamine. Revista Brasileira de Zootecnia, v.40, n.10, p.2186-2191, 2011.

TEIXEIRA, M.P.F.; BRAGA, J.F.V.; KLEIN, M.H.; ABREU, M.L.T. Avaliação comparativa da metodologia de determinação da área de olho de lombo em suínos (Sus domesticus).

Ciências Animal Brasileira, v.1-2, n.2, p.235-240, 2011.

UNIVERSIDADE FEDERAL DE VIÇOSA - UFV. SAEG. Sistema para análise estatística e genética. Versão 9.1. Viçosa, MG, 2008.

YAN, P.S.; YAMAMOTO, S. Relationship between thermoregulatory responses and heat loss in piglets.

Animal Science Journal, v.71, n.10, p.505-509. 2000.

Data de recebimento: 280/03/2013

Data de aprovação: 27/09/2013 